
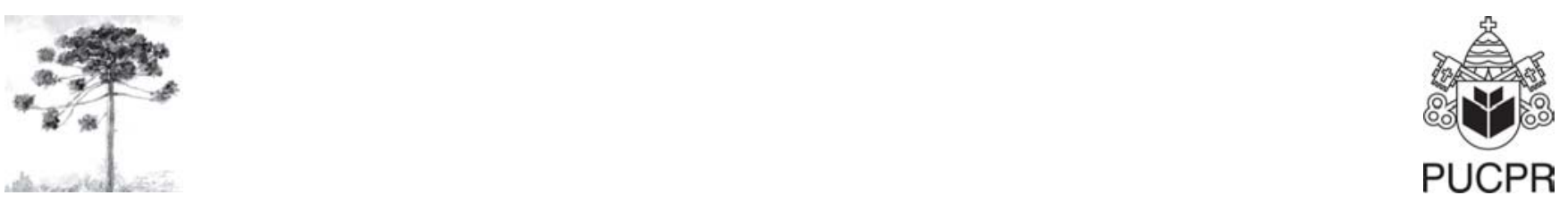

\title{
FORMAÇÃO DOS PROFESSORES DE CIÊNCIAS E BIOLOGIA: reflexões sobre os conhecimentos necessários a uma prática de qualidade
}

\author{
Formation of the sciences and biology teachers: reflections on \\ the necessary knowledge to practical one of quality
}

\section{Vera Maria Brito Malucelli}

Pontifícia Universidade Católica do Paraná, CCBS, Centro de Ciências Biológicas e da Saúde, Curitiba, PR - Brasil, e-mail: vecelli@uol.com.br

\begin{abstract}
Resumo
O objetivo deste estudo foi analisar criticamente a formação dos professores de Ciências e Biologia, refletindo sobre o que os professores deveriam conhecer-em um sentido mais amplo de "saber" e "saber fazer". Procurou-se, também, elementos de sustentação teórica, para as reflexões efetuadas sobre os fundamentos teóricos- filosóficos que melhoram a prática pedagógica de nossas escolas e orientam a formação dos profissionais dos cursos de Ciências e Biologia. No decorrer do trabalho, procurou-se enfocar quais os conhecimentos que os professores de Ciências e Biologia, em formação, precisam adquirir para o melhor desempenho de suas funções e que deve ir além de uma transmissão de conhecimentos e destrezas.
\end{abstract}

Palavras-chave: Formação de professores; Ensino de ciências; Reflexão; Atividade docente; Aprendizagem.

\begin{abstract}
The aim of this study was to make a critical analyzes about formation of sciences and biology teachers, reflecting on what these teachers would have to know a direction ampler "to know" and "to know to make". It was looked also, elements of theoretical support, for the reflections effected on the philosophical theoretical beddings that improving the pedagogical practice of our schools and guide the professionals formation of Sciences and Biology courses. At the elapse of the work had sought - in case that he hangs what the background as the teachers as of Sciences and Biology, well into formation, they need acquire for its best outstanding price as of your functions and that must moving beyond a transmission as of background and skills .
\end{abstract}

Keywords: Teachers formation; Education of sciences; Reflection; Research in education; Learning. 


\section{INTRODUÇÃO}

Refletir sobre o ensino de ciências sem integrar poucos iniciados nas ciências pode parecer uma ousadia. Este poderia ser um primeiro ponto para a nossa reflexão. O ensino de ciências participa de certo mistério, comuns às ciências ditas exatas, o mistério de ser um saber tão inacessível quanto nobre, se comparado a outros saberes.

A intenção deste artigo, a partir destas reflexões, é analisar as diferentes contribuições apresentadas, quando os grupos de professores abordam coletivamente a questão do que se deve "saber" e "saber fazer" por parte do professor de Ciências e Biologia, para ministrar uma docência de qualidade.

Quando se solicita a um professor em formação ou em exercício que expresse sua opinião sobre "o que os professores de ciências deveriam conhecer-em um sentido mais amplo de 'saber' e 'saber fazer', as respostas são, em geral, bastante pobres e não incluem muitos dos conhecimentos que a pesquisa destaca hoje como fundamentais" (1).

Esse fato pode ser interpretado como o resultado da pouca familiaridade dos professores com as contribuições da pesquisa e inovação didática. Mais do que isso, pode ser interpretado como expressão de uma imagem espontânea do ensino, concebido como algo essencialmente simples, para o qual basta um bom conhecimento da matéria, algo de prática e alguns complementos psicopedagógicos.

Pode-se chegar, assim, a pensar que os professores de Ciências não só carecem de uma formação adequada, como não são sequer conscientes de suas insuficiências. Como conseqüência, concebe-se a formação do professor como uma transmissão de conhecimentos e destrezas que, contudo, tem demonstrado reiteradamente suas insuficiências na preparação dos alunos e dos próprios professores.

É possível avançar na solução dessa séria contradição quando se tem em vista, na formação dos professores, as orientações construtivistas, cuja eficácia é demonstrada na aprendizagem dos alunos (2). Assim, o resultado é muito diferente quando essa questão é abordada por equipes de professores na perspectiva de um trabalho de (auto)-formação. Nesse caso, a produção dos grupos recolhe, em geral, um grande número de conhecimentos que estudos apontam como necessários, afastando-se, assim, de visões simplistas do ensino de Ciências.

É importante assinalar essa diferença, porque mostra até que ponto as carências e os erros que evidenciam a formação desses professores não são o resultado de incapacidades essenciais, pois ao se proporcionar aos professores a oportunidade de um trabalho coletivo de reflexão, debate e aprofundamento, suas produções podem aproximar-se dos resultados da comunidade científica. Trata-se, então, de orientar o trabalho de formação dos professores como uma pesquisa dirigida, contribuindo, assim, de forma funcional e efetiva, para a transformação de suas concepções iniciais.

Contribuições de grande riqueza têm sido apresentadas quando os grupos de professores abordam coletivamente a questão do que se deve "saber" e "saber fazer" por parte dos professores de Ciências, para ministrar uma docência de qualidade.

As diferentes contribuições, em geral, podem ser assim agrupadas: Conhecer a matéria a ser ensinada; conhecer e questionar o pensamento docente espontâneo; adquirir conhecimentos teóricos sobre a aprendizagem e aprendizagem de Ciências; possuir capacidade de crítica fundamentada no ensino habitual; saber preparar atividades; saber dirigir a atividade dos alunos; saber avaliar; utilizar a pesquisa e a inovação.

É evidente que as contribuições não possuem a clareza nem a profundidade de tratamento que oferecem os trabalhos publicados pelos pesquisadores. No entanto, essas contribuições vinculam-se aos poucos aspectos-chave sobre os quais a pesquisa está insistindo e permitem aos professores encontrar nos trabalhos publicados o reforço e a ampliação de sua própria produção.

Essas contribuições dos grupos de professores podem, também, mostrar até que ponto uma orientação construtivista - baseada na aprendizagem dos alunos, no tratamento de situações problemáticas abertas, na formação de equipes cooperativas e nos intercâmbios entre os referidos grupos - pode resultar efetivamente na formação dos professores.

A questão colocada anteriormente, "quais os conhecimentos que os professores de Ciências precisam, para abordar os problemas que a atividade docente lhes impõe”, dá lugar 
a contribuições dos diferentes grupos e a um debate em torno delas, que se transforma em um eficaz procedimento para romper com as visões simplistas que cada professor isolado costuma ter, e constitui, ainda, um possível fio condutor para abordar com um certo rigor a formação dos professores.

O debate sobre as diferentes contribuições permite, ainda, discutir as visões condutivistas, que contemplam cada "saber" ou "saber fazer" como algo que se pode adquirir com um treinamento específico proporcionado de fora e insistir no papel central que no processo de aquisição dos conhecimentos - e, em definitivo, em toda a atividade docente - deverá desempenhar a atividade inovadora e pesquisadora dos professores (3).

Embora a preocupação com o professor como um dos fatores essenciais do processo ensino/aprendizagem seja antiga (4), até recentemente os estudos centravam-se nas características do bom professor ou nas "diferenças entre bons e maus professores". Hoje, a questão se coloca em termos de quais são os conhecimentos que os professores precisam adquirir. Esse aspecto é importante e supõe uma superação de concepções essencialistas (do tipo: professor "é" ou "nasce" como tal), que indicavam ineficazes políticas de seleção, mais do que processos de formação.

O conjunto de conhecimentos e destrezas proporcionava uma visão rica e complexa da atividade docente que vai além, em alguns aspectos, do que se costuma indicar como "grandes objetivos" da formação dos professores. Isso deve ser ressaltado, mais uma vez, como resultado positivo, mas costuma gerar certo mal-estar entre os professores que, em geral, perguntam-se se tem sentido esperar que um professor chegue a possuir tantos conhecimentos, como os já enumerados, nas diferentes contribuições. É evidente que tal é impossível, mas é a própria questão que precisa de sentido. Assim, qualquer estudo sobre metodologia e epistemologia da Ciência revela certas exigências para o trabalho científico, tão amplas como as do trabalho docente. Contudo, a nenhum cientista é exigido que possua o conjunto de conhecimentos e destrezas necessárias para o desenvolvimento científico: é muito claro que se trata de uma tarefa coletiva. Do mesmo modo, o trabalho docente tampouco é, ou melhor, não deveria ser, uma tarefa isolada. Nenhum professor deve sentir-se vencido por um conjunto de saberes que, com certeza, ultrapassam as possibilidades de um ser humano. O essencial é que se possa ter um trabalho coletivo em todo o processo ensino/aprendizagem: da preparação das aulas até a avaliação.

Dessa forma, a complexidade da atividade docente deixa de ser vista como um obstáculo à eficácia e um fator de desânimo, para tornar-se um convite a romper com a inércia de um ensino monótono e sem perspectivas e, assim, aproveitar a enorme criatividade potencial da atividade docente. Trata-se, portanto, de orientar tal tarefa docente como um trabalho coletivo de inovação, pesquisa e formação permanente.

Essas são, sem dúvida, questões relevantes no momento de perguntar-se em que consiste a formação dos professores.

A simples soma de preparação científica e cursos gerais de educação como concepção de formação do professor parece ter resultado em fracasso. Assim, tem havido reiterados pronunciamentos, de vários autores, contra a incorreta orientação dos cursos de formação do professor e, em especial, contra "uma mera justaposição do tratamento dos conhecimentos científicos e de uma preparação psico-sóciopedagógica geral" $(5,6)$.

Esse modelo somatório de saberes acadêmicos, como base da formação dos professores de Ciências e Biologia, tem como principal obstáculo a falta de integração dos princípios teóricos estudados nos cursos de educação com a prática docente, o que é ressaltado sobre ângulos tão diversos, como as pesquisas sobre o pensamento e a tomada de decisões do professor. "Um dos principais problemas da formação de professores não é tanto o desenvolvimento do conhecimento dos alunos, das aulas e da natureza do processo educativo, e sim como facilitar aos professores em formação a integração destes conhecimentos dentro de sua própria prática" (6). Um programa eficaz na formação de professores deve integrar os conteúdos da disciplina, organizadores teóricos e os resultados da pesquisa sobre práticas bem-sucedidas e algumas experiências relevantes.

A didática das Ciências pode desempenhar um papel integrador, desde que reúna uma série de características - destacadas pela pesquisa educativa e aquela que se fez 
referência no decorrer deste trabalho, que podem ser, assim, sintetizadas:

a) estar dirigida à construção de um corpo de conhecimento específicos, capaz de integrar coerentemente os resultados das pesquisas em torno dos problemas propostos pelo ensino aprendizagem da disciplina;

b) deverá ser proposta como mudança didática do pensamento e comportamento docente "espontâneo";

c) estar orientada a favorecer a vivência de propostas inovadoras e a reflexão didática explícita;

d) deverá estruturar-se, a fim de incorporar o professor na pesquisa e inovação em didática das Ciências;

e) ser concebida, numa conexão direta com as práticas docentes, como núcleo integrador dos diferentes aspectos da formação docente.

Gil Péres (7), em seu trabalho Tendencias y experiencias innovadoras en la enseñanza de las Ciencias, reitera a necessidade de que a didática específica se configure como corpo técnico, capaz de integrar coerentemente os resultados das pesquisas em torno dos problemas concretos que se apresentam ao ensinar a disciplina.

Pode-se, ainda, dizer que as mudanças na licenciatura de Ciências e Biologia, que se fazem necessárias, não podem ser pensadas sem referência a uma política mais ampla, na qual educação e professor recebam outro tratamento. Reitera-se, então, a necessidade de não se dissociar a reflexão sobre currículo e sobre formação do professor da luta pela transformação das circunstâncias, que vêm impedindo que idéias e teorias já formuladas se materializem nas salas de aula de nossas Escolas e Universidades (8).

Os pontos aqui levantados, fruto da reflexão e da pesquisa sobre a formação dos professores no contexto dos cursos de Ciências e Biologia, precisam ser considerados com todo o cuidado por todos aqueles que se preocupam e pretendem agir sobre eles.

Essas reflexões não se restringem ao âmbito das instituições educacionais, pois o papel dos professores de Ciências e Biologia extrapola os muros da escola para interagir no social. O intelectual é mais que um professor que domina o conteúdo específico de sua área, ele é também um transmissor de conhecimento, um mediador, legitimador e produtor de idéias e práticas sociais.

\section{REFERÊNCIAS}

1. Pérez G, Carrascosa J, Furió C, Martínez Torregrosa J. La enseñanza de las ciencias en la educación secundaria. Barcelona: Horsori; 1991.

2. Gené A, Perez G. La Formación del profesorado com cambio didáctico. Revista Interuniversitária de Formación del Profesorado. 1988;2:155-159.

3. Gimeno J. El perfeccionamento como desarrollo de la professionalidad docente. In: Gil, D. (Org.). La Formación de Formadores en Didáctica de las Ciencias. Valência: Gulbekian; 1990.

4. Bricones I, Fuentes A, Nieda J, Palacios M., Otero J. Indentificación de comportamientos y características deseables del profesorado de ciencias experimentales del bachilerado. Enseñanza de las Ciências. 1986;4(3):209-222.

5. Pérez, 6, Qué han de saber y saber hacer los profesores de ciencias? Enseñanza de las ciencias. 1982;9(1):69-77.

6. Carvalho AMP. de. Reformas nas licenciaturas: a necessidade de uma mudança curricular. Instituto Nacional de Estudos Pedagógicos. 1993;54:51-64.

7. Gil P, Carrascosa J, Furió C, Martínez TJ. La enseñanza de las ciencias en la educación secundaria. Barcelona: Horsori; 1991.

8. Malucelli, Vera Maria Brito. A Formação dos Profissionais da Educação no Contexto dos Cursos de Biología. [dissertação]. Curitiba: PUCPR; 2001.

Recebido: 05/08/2006

Received: 08/05/2006

Aceito: 30/11/2006

Accepted: 11/30/2006 